fewer suffer from the former. The degree of coronary atheroma discovered in persons killed accidentally has been studied in many parts of the world, and the condition has been found to be equally widely distributed in the United States and United Kingdom. Yet, in contrast, the mortality from ischaemic heart disease is markedly different in comparable populations, the U.S.A.F.:R.A.F. ratio approximating to $10: 1 .^{2}$ The opinion expressed by Kannel ${ }^{3}$ that it is the presence of an effective collateral circulation which determines the clinical picture offers a reasonable explanation of the anomaly.

Carboxyhaemoglobin is easily determined and is therefore a convenient marker of the products of combustion. It is possible that, because of this, carbon monoxide is being artificially promoted as a cause of disease. Workers in Los Angeles 4 have attempted to relate atmospheric $\mathrm{CO}$ levels to an increased fatality rate from myocardial infarction; in fact, any relationship must be attributed to atmospheric pollution as a whole. In the same way, postmortem studies designed to show atherogenic properties of cigarette smoke $^{5}$ fail to take into account the life style of heavy smokers.

The case for an association between smoking and ischaemic heart disease seems proved beyond doubt. But rather than to attribute an atherogenic property to cigarettes in general and carbon monoxide in particular (Dr. Wald and his colleagues do not claim this to be necessarily so), it might be more valid, and in keeping with the "collateral" theory, to suggest that the carboxyhaemoglobin results reported by them were more significantly reflecting the levels of nicotine, which is known to have a marked pharmacological effect on the cardiovascular system. -I am, etc.,

J. K. Mason

R.A.F. Institute of Pathology and Tropical Medicine, Halton, Aylesbury, Bucks

1 Morris, J. N., and Dale, R. A., Proceedings of 2 the Royal Society of Medicine, 1955, 48, 667.

Kannel, W. B., New England Fournal of Medicine,

1970, 282, 1153 .
Cohen, S. I., Deane, M., and Goldsmith, J. R., S10.

5 Auerbach, O., Hammond, E. C., and Garfinkel, 273, 775 .

\section{Löffler's Syndrome}

SIR,-I am grateful to Dr. Alex Sakula for his letter (7 April, p. 54) referring to the case reported by myself and Dr. C. C. Bailey (24 February, p. 460) of a 4-year-old boy with lymphosarcoma presenting as Löffler's syndrome. As Dr. Sakula reaffirms, Löffler's syndrome refers to a transient condition of eosinophilia with pulmonary radiological opacities; though originally described in association with Ascaris lumbricoides infestation the same syndrome has been observed in a multitude of conditions since then and is thought to be an allergic manifestation.

We described this case as Löffler's syndrome because the lung changes were typical of this condition radiologically; they cleared within a few weeks, as the eosinophilia subsided, in response to steroid therapy. The radiological appearances have not recurred, even when the patient eventually developed his florid lymphosarcoma. We feel that this is adequate evidence that the lung changes were part of an "eosinophilia syndrome" which is known as Löffler's syndrome, and not that they were, as Dr. Sakula suggests, due to lymphosarcomatous infiltration. To the best of our knowledge Löffler's syndrome, which has been described in association with many and varied conditions, has never before been observed with lymphosarcoma.-I am, etc.,

Royal Hospital,
Sheffield

Richard H. Campbell

\section{Advertising of Antibiotics}

SIR,-I should like the opportunity to comment on the letter from Drs. J. D. Williams and A. M. Geddes (14 April, p. 116), particularly with reference to the paragraph about cephradine. First they refer to the "advertising booklet produced by one of the companies" and at the end of the letter they "urge [the pharmaceutical companies'] medical departments to curb the enthusiasm of commercial colleagues in the content of their promotional literature." The publication referred to is a technical booklet available usually on request. This is prepared by the medical department for the purpose of providing technical information and, as such can hardly be described as promotional.

Unfortunately at the time of the launching of cephradine the only in vitro figure we had available in the United Kingdom for the minimum inhibitory concentration agains penicillinase-producing staphylococci was the one quoted. This was against one strain available in the Squibb Institute, New Jersey The claim that cephradine is effective was based on clinical and bacteriological evidence in trials, using the disc sensitivty test. In common with your correspondents we noted the discrepancy between mean inhibitory and peak serum concentrations and initiated further in vitro tests which have been carried out in a number of hospital laboratories in this country. These have shown that the minimum inhibitory, and indeed bactericidal concentration for the penicillinase-producing organisms to be almost invariably below the mean peak serum concentration following a $500-\mathrm{mg}$ dose of cephradine.

Drs. Williams and Geddes also criticize the fact that cephradine's sensitivities are compared only with those of ampicillin, tetracycline, and chloramphenicol. I agree that it might have been more helpful to include other antibiotics, but it is logical surely to compare it with three widely used broadspectrum antibiotics. While agreeing that chloramphenicol should be prescribed onl for limited indications, in a world-wide company it was necessary to carry out this research bearing in mind the most common alternatives. Regrettable though it may be, chloramphenicol is still widely prescribed throughout the world and, to judge by last years' prescription figures, there has either been a higher incidence of typhoid than notified or else it is still being prescribed for less serious conditions in the United Kingdom. Is showng that a cephalosporin compares favourably with a more toxic alternative to be deprecated? - I am, etc.,

T. K. Clarke Medical Adviser, Twickenham, Middlese
"Hypersensitivity Hepatitis" Associated with Administration of Cyclizine

SIR,-Cyclizine (1-benzhydryl-4-methyl piperazine) hydrochloride, an antihistamine used mainly in the prevention and treatment of nausea and vomiting, has been available since 1954. During this time there has been no reported case of jaundice attributable to the drug. Nevertheless, we have recently seen a patient in whom a diagnosis of "hypersensitivity hepatitis" induced by cyclizine seems very likely.

The patient, an 8-year-old white girl, became ill with malaise, anorexia, nausea, vomiting, and jaundice in the middle of July 1972. The serum bilirubin concentration was $5.5 \mathrm{mg} / 100 \mathrm{ml}$, serum alanine aminotransferase (SGPT) 460 units, and alkaline phosphatase 45 K.A. units. Hepatitis B antigen was not found in the serum. A diagnosis of infective hepatitis was made and she was treated with bed rest alone. There were no known cases of infective hepatitis in the patient's family, among her friends, or at her school at that time. Starting eight days before the onset of the illness, she had taken $25 \mathrm{mg}$ of cyclizine hydrochloride by mouth daily for five days to prevent motion sickness. She had not previously received this drug and had taken no others recently. There was a strong family history of penicillin sensitivity and the patien had on a number of occasions developed diarrhoea while receiving that antibiotic; whether or not the latter was due to penicillin sensitivity is not known. By the end of August she was well enough to return to school. On 24 September she was again given $25 \mathrm{mg}$ of cyclizine by mouth to prevent motion sickness. The following day she felt ill and her urine was noted to be dark, and a day later jaundice was obvious. Her urine contained $1+$ urobilin and $2+$ bilirubin the serum bilirubin level was $5.2 \mathrm{mg} / 100 \mathrm{ml}$ SGPT 400 units, and alkaline phosphatase 37 K.A. units. The serum was again negative for hepatitis B antigen. She was treated with bed rest alone. Eight weeks passed before she was considered well enough to get up and 16 weeks before the serum bilirubin level returned to normal. Liver biopsy was not performed. The patient's serum was examined for antibodies against cyclizine hydrochloride: both cyclizine-induced Coombs test and a Coombs consumption test for "anti-liver" antibodies were positive. These tests were negative when re peated on the serum of other individuals re ceiving cyclizine and on jaundiced patients who had not taken the drug. An attempt to induce the patient's lymphocytes to transform with cyclizine failed.

While accepting that acute viral hepatitis cannot entirely be excluded as the cause of our patient's illness, we believe that the recurrence of hepatitis following an in advertent challenge with cyclizine and the serological findings are more in keeping with hypersensitivity reaction to the drug. The mechanism or mechanisms involved in "hypersensitivity (or allergic) hepatitis" have not been elucidated, but in some cases the drug is presumed to act as a hapten. This may explain our failure to induce the patient's lymphocytes to transform when exposed to cyclizine.-We are, etc.,

M. C. KEW J. SEGEI A. ZOUTENDYK

University of the Witwatersrand
South African Institute for Medical Research South African

\section{Arterial Haemorrhage in a Drug Addict}

SIR,-The recent paper by Mr. R. Pollard (31 March, p. 784) discussing some surgical complications of intravascular injections in 